anales de psicología / annals of psychology

2020, vol. 36, $\mathrm{n}^{\circ} 1$ (january), 102-110

https://doi.org/10.6018/analesps.326531
(C) Copyright 2020: Editum. Servicio de Publicaciones de la Universidad de Murcia. Murcia (Spain) ISSN print edition: 0212-9728. ISSN on line edition (http://revistas.um.es/analesps): 1695-2294.

On line edition License Creative Commons 4.0: BY-NC-ND

\title{
Differential analysis of executive functions in children from disadvantaged families vs. children with autism spectrum disorder
}

\author{
M. Mar Gómez-Pérez ${ }^{1,2 *}$, and M. Dolores Calero ${ }^{1}$ \\ 1 Centro de Investigación Mente, Cerebro y Comportamiento (CIMCYC), University of Granada (Spain) \\ 2 Department of Psychology, University of Jaén, Jaén (Spain)
}

\begin{abstract}
Título: Análisis diferencial de las funciones ejecutivas en niños pertenecientes a familias desfavorecidas vs. niños con trastorno del espectro autista.

Resumen: Las Funciones Ejecutivas (FE) se consideran necesarias para afrontar nuevas situaciones y para controlar la propia conducta. Diversos estudios han confirmado que poblaciones tan diferentes como niños con Trastorno del Espectro Autista (TEA) y niños de familias desfavorecidas (FD) muestran dificultades en las FE. Este estudio pretende examinar las dificultades en $\mathrm{FE}$ en esas dos poblaciones con respecto a las $\mathrm{FE}$ en niños que muestran un desarrollo típico (DT). Un total de 89 niños de edades comprendidas entre los 7 y 12 años, divididos en tres grupos, participaron en el estudio: 28 con TEA, 36 de FD y 25 con DT. La evaluación se realizó con diferentes medidas de FE (memoria de trabajo, flexibilidad cognitiva, inhibición, planificación y autorregulación) y coherencia central. Los resultados muestran que, en general, los niños de FD obtuvieron las menores puntuaciones en todas las medidas, aunque las diferencias no fueron significativas en todos los casos. Los niños con TEA obtuvieron puntuaciones similares al grupo DT en planificación y memoria de trabajo, y mayores puntuaciones en coherencia central. Además, cuando se les compara con los niños de FD, los niños con TEA obtuvieron una ejecución mayor en todas las medidas. Estos resultados indican que existen diferencias entre grupos y, por tanto, que los programas de intervención diseñados para cada uno de ellos deben centrarse en diferentes tipos de tareas.

Palabras clave: Dificultades: Funciones ejecutivas; Trastorno del espectro
\end{abstract} autista; Familias desfavorecidas; Infancia; Coherencia central.

\section{Introduction}

The term Executive Functions (EF) refers to a number of higher-order, interrelated neurocognitive processes that are involved in organizing action and thought; they are considered necessary to deal with new, complex situations involving objectives or goals for which we have no established, automated behavior (Blijd-Hoogewys, Bezemer, \& Van Geert, 2014; Diamond, 2013; Hill, 2004). The processes involved are cognitive flexibility (the ability to change between different tasks), inhibitory control (the ability to stop a behavior, ignore certain information or control impulses), working memory (the ability to keep certain relevant information activated for a task while it is under way), planning (the ability to develop a plan of action, as well as to reassess and modify it), initiation of behavior (related to starting new activities), and self-regulation (a skill related to monitoring and controlling one's own actions, as well as correcting and updating them) (Blijd-Hoogewys et al., 2014; Diamond, 2013; Hill, 2004).

* Correspondence address [Dirección para correspondencia] M. Mar Gómez-Pérez. Centro de Investigación Mente, Cerebro y Comportamiento (CIMCYC), University of Granada, Campus Cartuja S/N, 18071 (Spain). E-mail: mgomezp@,ugr.es

(Article received: 4-4-2018; revised: 8-12-2018; accepted: 14-9-2019)
Abstract: Executive Functions (EF) are considered necessary for dealing with new situations and for controlling one's behavior. Studies have confirmed EF difficulties in children with autism spectrum disorder (ASD) and in children from disadvantaged families (DF). This study aimed to examine EF difficulties in the two populations -ASD and DF children- with respect to $\mathrm{EF}$ in children who show typical development (TD). A total of 89 children between the ages of 7 and 12 years participated, divided into three groups: 28 with ASD, 36 from DF and 25 with TD. Assessments were made with different measures of EF (working memory, cognitive flexibility, inhibition, planning and self-regulation) and central coherence. In general, the children from DF obtained the lowest scores in all measures, although differences were not significant with respect to the other groups in all cases. Children with ASD obtained similar scores to the TD group in executive attention and working memory, and higher scores in central coherence. In comparison to the children from DF, the ASD children did better on all measures. These results would indicate that intervention programs designed for the two groups must be focus on different kind of tasks.

Keywords: Difficulties; Executive functions; Autism spectrum disorder; Disadvantaged Families; Childhood; Central coherence.
Development of EFs begins in early childhood and becomes consolidated around the age of 20 years, with three main stages of development: childhood (ages 6-8 years), middle childhood (ages 9-12 years) and adolescence (ages 1316 years) (Brocki \& Bohlin, 2004; Hill, 2004). However, these periods are not absolute, because there are idiosyncratic differences and differential trends in the development of EF component processes, considering a good time to evaluate its development from 7-8 years (Huizinga, Dolan, \& Van der Molen, 2006). EFs can predict academic, social and work success throughout an individual's lifetime; they are considered important to good adjustment and to success in the social and family context, to good physical and mental health, etc. Similarly, deficits in EFs hinder people's independence, affecting their problem solving processes, decision making, adaptation to the environment, inhibition of inappropriate behavior that may offend others, and the generalization of learning (Diamond, 2013; Hill, 2004).

Because of the great impact of EFs in a person's life, they have been studied widely in different populations. Prior studies show that many psychological disorders and illnesses, such as spina bifida, cerebral palsy, schizophrenia, dyslexia, attention deficit with hyperactivity disorder, autism spectrum disorder, as well as others, are accompanied by deficits in EF, which hinder their adaptation to the environment 
(Iampietro, Giovannetti, Drabick, \& Kessler, 2012; Moura, Simões, \& Pereira, 2015; Piovesana, Ross, Whittingham, Ware, \& Boyd, 2015; Salomone, Fleming, Bramham, O’Connell, \& Robertson, 2016; Zabel et al., 2011).. In addition, deficits in EF are observed in some populations with social difficulties, such as children from disadvantaged families (Devicienti \& Poggi, 2011; Dickerson \& Popli, 2016). In the present study we focus on the comparison between EF difficulties presented by children with autism spectrum disorder (Brunsdon et al., 2015) and children from disadvantaged families (Raver, Blair, \& Willoughby, 2013).

Children who grow up in disadvantaged families (DF) show a negative impact on their cognitive, social and emotional development. A family is considered to be in a disadvantaged situation when there is difficulty meeting basic needs such as housing, education, employment, healthcare, safety, and so on (Bäckman \& Nilsson, 2011; Devicienti \& Poggi, 2011). Although this situation is closely related to low socioeconomic status and some of its important factors, such as poverty and unemployment, a disadvantaged situation is considered to be a multi-factor phenomenon involving additional factors such as family structure or origins, parental psychopathology, social and emotional competence, economic and educational resources, and other factors having a positive or negative influence (Bäckman \& Nilsson, 2011; Devicienti \& Poggi, 2011). Studies to date suggest that the deficits found are due to psychosocial deprivation experienced by these children during their main developmental years.

Cognitive development is affected by poverty, such that the longer the exposure to poverty, the greater its negative effects on cognitive skills (Dickerson \& Popli, 2016). It is therefore not surprising that different studies find EF deficits in children who live in disadvantaged families, even at young ages; they perform poorly on tasks related to cognitive flexibility, inhibitory control, working memory and planning (Arán-Filippetti, 2013; Arán-Filippetti \& Richaud de Minzi, 2011; Mata, Gómez-Pérez, Molinero, \& Calero, 2017; Raver et al., 2013; Rhoades, Greenberg, Lanza, \& Blair, 2011). Neuroimaging research has indicated that socioeconomic status consequences may influence the level of brain activation and be associated with atypical structural development of brain areas that support EF (Hair, Hanson, Wolfe, \& Pollak, 2015; Ursache \& Noble, 2016).

Children with Autism Spectrum Disorders (ASD) are characterized by persistent deficits in social interaction and communication, in nonverbal communicative behaviors, in developing and understanding social relations and by repetitive, restrictive and stereotyped behavior patterns (Diagnostic and Statistical Manual of Mental Disorders, 5th ed.; DSM-5; American Psychiatric Association, APA, 2013). Different theories have been developed to explain their behavioral characteristics and social functioning. On the one hand, the hypothesis of Weak Central Coherence (WCC) (Frith, 1989; see Aljunied \& Frederickson, 2013) considers information processing and patterns of perception and attention to be skewed in subjects with ASD. This hypothesis postulates that such subjects present a bias in specific processing, leading them to focus on details. This makes them superior to other subjects in recalling specific information, while at the same time they fail to ascertain the global meaning. They find it difficult to understand the general message and to form broad, general ideas that can be transferred to different contexts (Aljunied \& Frederickson, 2013; Booth \& Happé, 2018; Brunsdon et al., 2015). On the other hand, according to the theory of executive dysfunction, deficits in EF may be responsible for these behavioral characteristics (see Hill, 2004). This idea is supported by recent studies that find a relationship between EF and social functioning in ASD (Leung, Vogan, Powell, Anagnostou, \& Taylor, 2016; Peterson, Noggle, Thompson, \& Davis, 2015; Pugliese et al., 2016), suggesting that adaptation and social interaction problems are influenced by deficits in EF.

The main underpinnings for this theory are found in studies where ASD subjects present difficulty across a range of EFs, including cognitive flexibility, inhibition and working memory (Blijd-Hoogewys et al., 2014; Mostert-Kerckhoffs, Staal, Houben, \& De Jonge, 2015; Van Eylen, Boets, Steyaert, Wagemans, \& Noens, 2015). However, there are also studies indicating that subjects with ASD show similar executive functioning to that of the typical population (De Vries \& Geurts, 2012; Troyb et al., 2014). There are even studies that indicate the coexistence of deficits in certain EFs, but high functioning in others (Brunsdon et al., 2015; Robinson, Goddard, Dritschel, Wisley, \& Howlin, 2009).

These contradictory results may be due to the heterogeneity of subjects with ASD, whether in IQ, language skills, metacognition and severity of their symptoms (BlijdHoogewys et al., 2014; De Vries \& Geurts, 2014; Kalbfleisch \& Loughan, 2012; Van Eylen, et al., 2015). Alternatively, these results may be due to variability in the measures used in the different studies, ranging from direct performance measures to parental reports (Gómez-Pérez, Calero, Mata, \& Molinero, 2016; Leung \& Zakzanis, 2014; Troyb et al., 2014; Van Eylen et al., 2015).

Because of the importance of EF in daily life, and based on the EF difficulties seen in children from both groups--in ASD children due to their disability and in children from DF due to the contextual deficits they are exposed to--we consider it of interest to examine whether these EF deficits are comparable in the two groups. We wish to confirm whether the different causes for EF deficits in these two populations lead to differences in their performance levels and the type of deficits present. If we clearly delimit the deficits of each population, we will be able to more easily adapt intervention programs to the needs of each group.

Therefore, the present study analyzed whether the deficits in EF were comparable in nature, and in particular, whether there were differences between a group of children with ASD without accompanying intellectual or language impairment, a group of children from disadvantaged families and a group of children with typical development, on: 
- Measures of several executive functions: working memory, cognitive flexibility, inhibition, planning and self-regulation. As a hypothesis, we expected to find significant between-group differences, and that the group of children with typical development would have the best scores, in comparison to the other two groups.

- Measures of central coherence. We expected that children with ASD would obtain the highest scores, meaning significantly weaker central coherence than the other two groups.

\section{Method}

\section{Design}

This study followed an ex post facto design with three comparison groups of children (children with ASD, children from DF and children with typical development).

\section{Participants}

The three groups of study participants comprised a total of 89 Spanish children, between the ages of 7 and 12. One group of 28 children were diagnosed with ASD without accompanying intellectual or language impairment (23 boys and 5 girls), where $M_{\text {age }}=9.79(S D=1.75)$ and IQ $M=97.33$ $(S D=15.19)$; these children belonged to different ASD associations in Andalusia. Another group of 36 children were from disadvantaged families (DF) (18 boys and 18 girls), where $M_{\text {age }}=9.39$ (SD = 1.34) and IQ $M=90.08$ (SD = 12.88); these came from different Andalusian schools with children from disadvantaged families. And 25 children (15 boys and 10 girls) with typical development (TD), where $M_{\text {age }}$ $=9.20(S D=1.44)$ and IQ $M=96.28(S D=11.85)$; these also came from different Andalusian schools.

The three groups were matched in age and IQ, but not in gender. Univariate analysis of variance (ANOVA) showed that there were no significant differences in age $F(2,86)=$ $1.07, p=.349$, partial $\eta^{2}=.02$, s.p. $=.23$ or in total IQ, assessed by the WISC-IV (Wechsler Intelligence Scale for children - IV; Wechsler, 2005), $F(2,86)=2.77, p=.068$, partial $\eta^{2}=.06$, s.p. $=.53$. In gender, however, the Chi square showed significant differences in between-group distribution, $\chi^{2}=7.10, p=.029$, where the ASD group had a smaller number of girls and a larger number of boys.

General inclusion criteria were established as age between 7 and 12, total IQ between 70 and 130 on the WISC$\mathrm{IV}$, and having a prior diagnosis (ASD and DF groups) from the specialized professionals at the children's respective associations and schools, using the Andalusian standard protocols. Having a prior diagnosis of ASD without accompanying intellectual or language impairment was established as a specific inclusion criterion for the ASD group (or Asperger syndrome if the diagnosis preceded the DSM-5); based on assessments with ADOS (Autism Diagnostic Observation Schedule;
Lord, Rutter, DiLavore, \& Risi, 2002) and ADI-R (Autism Diagnostic Interview-Revised; Rutter, LeCouteur, \& Lord, 2000), as well as an overall assessment of their skills. The specific inclusion criterion for the DF group was the existence of a psychosocial risk report issued by the Social and Child Protection Services of the Andalusian Regional Government. Psychosocial risk reports were produced as indicated after administration of the Child Well-Being Scales to all the families (Magura \& Moses, 1986; Spanish adaption De Paúl \& Arruabarrena, 1999). This instrument determines the extent to which children's families satisfy their basic material, emotional, educational and social needs. A total of 43 scales provide information on four areas of care-parental role performance, familial capacities, child role performance, and child capacities - with possible scores ranging from 0 (indicating the most serious conditions) to 100 (indicating adequate conditions); scales are completed by a professional that knows the family and has recently visited the home. Each scale point is weighted in terms of a common dimension and the seriousness of the condition. Finally, the instrument provides a total score and a score for each factor: household adequacy, parental disposition and child performance. Reliability of the different scales falls between .71 and .90 (alpha index) and between .69 and .93 (internal consistency) (De Paúl \& Arruabarrena, 1999).

Exclusion criteria for the DF and ASD groups were established as presenting co-morbidity with any disorder or clinical problem, according to the reports submitted by the professionals who made the diagnosis.

\section{Instruments}

\section{Executive Functions measures}

Working Memory Index of the WISC-IV (Wechsler, 2005). This assesses capacity for retaining and storing information, and for mentally operating with this information, transforming it and generating new information. It is applicable in children from the ages of 6 and 16 and it takes around 10-15 minutes. It consists in two subtests, Digits and Letter-Numbers. Digits has two parts (1) digits forward where children are required to repeat from 3 to 9 digits in the same order; and (2) digits backwards where children are required to repeat from 3 to 9 digits in the inverse order. Letters-Numbers where is presented a mixed series of numbers and letters and children should rearrange it such that numbers come first, from lowest to highest and after letters in alphabetical order. The average reliability coefficient for Digits and for Letters-Numbers is 0.84 , and 0.89 for the total Working Memory index.

Wisconsin Card Sorting Test-64 (WCST-64); Kongs, Thompson, Iverson \& Heaton, 2000. The WCST-64 uses only the first 64 cards of the WCST, with the same administration criteria and purpose as the standard WCST (Heaton, 1981). This test measures executive functions (such as strategic planning, cognitive 
flexibility, inhibition and perseverance and selfregulation), category formation and environmental feedback to shift cognitive sets. It is applicable in children from the ages of $61 / 2$ and 89 and it takes around 20-25 minutes. Participants have to sort the cards following some matching-criteria (color, shape, number), as a function of the experimenter's feedback (that is, the participant was told whether a particular match is right or wrong). The matching-criteria changed after 10 consecutive correct matches, but without explicit instruction to the participant. The WCST provides information on the number of correct answers, number of perseverations, and number of conceptual-type responses (responses showing comprehension of the classification principles) in each test phase. Like the standard version, this test also obtains good reliability and validity data (Greve, 2001).

Stroop: Color and Word test (Golden, 2006). This test is a measure of inhibitory control, assessing attentional control. It is applicable in ages from 7 to 80 and it consists of three tasks with duration of 45 seconds each. The tasks are word reading (Stroop-Word), where the subject must read the written names of colors; color naming (Stroop-Color), where he or she must name the color of the typeface; and color-word (Stroop-Color-Word), naming the color of the typeface and ignoring any conflict with the word meaning, which measures inhibitory control. An interference index is also obtained (Stroop-Interference), measuring interference in the subject and his or her attention control. Test-retest reliability is .89 for Stroop-Word, .84 for Stroop-Color, .73 for Stroop-Color-Word and .70 for Stroop-Interference (Golden, 2006).

\section{Central Coherence measures}

Group Embedded Figures Test (GEFT; Witkins, Oltman, Raskin \& Karp, 1987). The group format of the EFT, like its original format, is a measurement of field dependence/independence (central coherence), where the subject must find a simple figure within another more complex one. It is applicable in wide range of age from 5 to adulthood and it consists of three parts, one of training and two of test, with duration 2, 5 and 5 minutes respectively. This test provides a general score that is obtained from the sum of the correctly found elements in sections two and three; a higher score represents greater field independence. Estimated reliability analysis of this version of the EFT produced a score of .82; validity has been analyzed using several tests, where analyses performed with the EFT obtain better data, reporting correlations between -.82 and -.63.

Block Design Subtest of the WISC-IV Perceptual Reasoning Index (Wechsler, 2005). This assesses subjects' spatial visualization and analysis, simultaneous processing, visual-motor coordination, dexterity, nonverbal concept formation, as well as planification In addition, describes one's skills in mentally "putting together" complex objects by seeing and mentally manipulating it's individual parts. It is applicable in children from the ages of 6 and 16 and it takes around 10-15 minutes. The test is nine red and white square blocks and cards showing different color designs that can be made with the blocks. The child must arrange the blocks to match the design. The block design subtest provides a punctuation about correct designs in combination with speed. According to Shah and Frith (1993), this measure is favored by weak central coherence. The reliability coefficient is .84 .

\section{Procedure}

First, permission was obtained from the Human Research Ethics Committee at the University of Granada. For the selection of participants, voluntary participation was requested from ASD associations and from schools with children from disadvantages families in several Andalusian cities. A preselection of participants was made by psychologists from associations and schools, based on the children's diagnostic reports and the inclusion criteria established. Next, the children's parents were asked whether they wished their children to participate in the study; if they agreed, informed consent was obtained before including children in the study. A total of 95 children were assessed, but six of these children were excluded from the data analysis due to presenting an IQ below 70 .

Children from DF belonged to families with low socioeconomic status, low levels of education, and social difficulties that put them in a social exclusion situation, such as psychosocial risk reports issued by the Social and Child Protection Services indicate. On the other hand, the ASD and TD children belonged to families with medium socioeconomic status, medium levels of education, and without social difficulties that would place them in a situation of social exclusion or at risk thereof, according to the psychosocial risk reports data.

Participants were individually assessed in three sessions of approximately forty-five minutes each, with two days between session and session. Test application was counterbalanced between the sessions.

\section{Data analysis}

We use the SPSS statistical package, version 21.0, for the data analysis. First, we checked the assumptions of sample normality and homogeneity with the Kolmogorov-Smirnov and Levene statistical tests, respectively.

After analyzing the results and verifying that the sample meets these assumptions, we chose multivariate analysis of variance (MANOVA) in order to compare the ASD, DF and TD groups in the measures' scores obtained: performance on working memory index, digit span, letters-numbers, WCST-64-Correct answers, WCST-64-perseverations and WCST-64-concept level answers, Stroop-Color-Word and Stroop-Interference. Univariate analysis of variance (ANOVA) was carried out for GEFT correct answers and the 
Block Design correct answers. Bonferroni post hoc analyses were applied at level of significance $p<.05$.

\section{Results}

The main objective of this study was to verify whether there were differences on different measures of executive functions between children with ASD without accompanying intellectual or language impairment, children from DF and children with TD.

In the case of working memory, assessed by the WISCIV (working memory index, digit span and letters-numbers subtests), MANOVA results showed significant betweengroup differences in working memory measures $\Lambda=0.84$, $F(4,70)=3.90, p=.005$, partial $\eta^{2}=.08$, s.p. $=.89$. The uni- variate analyses showed significant differences in the Working Memory Index $(p=.009)$, Digit Span $(p=.031)$ and Letters-Numbers $(p=.009)$, with small effect sizes (see Table 1). Post hoc analysis of the Working Memory Index indicated significant differences between the DF and TD groups $(p=$ $.023)$, and between DF and ASD children $(p=.032)$, but not between the ASD and TD groups $(p=.999)$; there were significant differences on Digit Span between the DF and ASD groups $(p=.026)$, but not between the ASD and TD groups $(p=.401)$ or between the DF and TD groups $(p=.962)$; and on Letters-Numbers between the DF and TD groups $(p=$ $.009)$, but not between the ASD and TD groups $(p=.972)$, or the ASD and DF groups $(p=.124)$. In all significant cases, the children from DF had lower scores.

Table 1. Mean Differences of Working Memory Measures, WCST-64, Stroop, GEFT and Block Design Subtest, between TD, DF and ASD Groups.

\begin{tabular}{|c|c|c|c|c|c|c|c|c|}
\hline \multirow[b]{2}{*}{ Variable } & \multicolumn{2}{|c|}{$\begin{array}{c}\text { TD Group } \\
(n=25)\end{array}$} & \multicolumn{2}{|c|}{$\begin{array}{c}\text { DF Group } \\
(n=36)\end{array}$} & \multicolumn{2}{|c|}{$\begin{array}{c}\text { ASD Group } \\
(n=28)\end{array}$} & \multirow[b]{2}{*}{$F_{(2,86)}$} & \multirow[b]{2}{*}{ partial $\eta^{2}$} \\
\hline & $M$ & $S D$ & $M$ & $S D$ & $M$ & $S D$ & & \\
\hline \multicolumn{9}{|l|}{ WM Measures } \\
\hline WM Index & 26.80 & 5.85 & 22.58 & 5.00 & 26.50 & 7.05 & $5.01 * *$ & .10 \\
\hline Digits Span & 12.84 & 2.25 & 12.25 & 1.46 & 13.79 & 3.02 & $3.62^{*}$ & .08 \\
\hline Letters-Numbers & 13.96 & 4.25 & 10.33 & 4.39 & 12.71 & 5.02 & $5.03 * *$ & .11 \\
\hline \multicolumn{9}{|l|}{ WCST-64 } \\
\hline Correct Answers & 34.32 & 10.91 & 30.33 & 9.26 & 33.67 & 12.82 & 1.21 & .03 \\
\hline Perseveration Answers ${ }^{\star}$ & 17.84 & 14.77 & 16.58 & 12.60 & 20.52 & 17.60 & 0.56 & .01 \\
\hline Concept Level Answers & 26.36 & 13.17 & 21.86 & 12.15 & 25.59 & 16.49 & 0.95 & .02 \\
\hline \multicolumn{9}{|l|}{ Stroop } \\
\hline Color-Word & 46.80 & 5.45 & 41.56 & 6.37 & 44.64 & 7.85 & $4.79 *$ & .10 \\
\hline Interference ${ }^{\star}$ & -0.10 & 4.77 & -0.48 & 4.65 & 3.14 & 7.24 & $3.68^{*}$ & .08 \\
\hline \multicolumn{9}{|l|}{ GEFT } \\
\hline Correct Answers & 3.24 & 3.46 & 2.64 & 2.63 & 6.85 & 4.75 & $11.58^{* *}$ & .21 \\
\hline \multicolumn{9}{|l|}{ Block Design Subtest } \\
\hline Correct Answers & 24.00 & 11.62 & 25.65 & 7.70 & 32.62 & 14.02 & $4.68^{*}$ & .10 \\
\hline
\end{tabular}

Note: TD Group: Children with Typical Development Group; DF Group: Children form Disadvantaged Families Group; ASD Group: Children with Autism Spectrum Disorder Group; WM Measures: Working Memory Measures; WCST-64: Wisconsin Card Sorting Test-64; Stroop: Stroop Color and Word Test; GEFT: Group Embedded Figures Test

${ }^{\star}$ Inverse variable

${ }^{*} p<.05 ;{ }^{*} p<.01$

As for the WCST-64 assessments of Correct Answers, Perseveration Answers and Concept Level Answers, MANOVA results did not show statistically significant differences between the groups $\Lambda=0.93, F(6,168)=1.07, p=$ .384 , partial $\eta^{2}=.04$, s.p. $=.41$ on WCST-64 measures. Specifically, univariate analyses did not show significant between-group differences on the different measures: WCST64-Correct Answers ( $p=.303)$, WCST-64-Perseveration Answers $(p=.575)$, or WCST-64-Concept Level Answers $(p=$ .392) (see Table 1).

In inhibitory control, assessed by Stroop, MANOVA results showed significant between-group differences $\Lambda=0.72$, $F(4,170)=7.60, p=.000$, partial $\eta^{2}=.15$, s.p. $=1.00$. The univariate analyses revealed significant differences on Stroop-Color-Word $(p=.011)$, and Stroop-Interference ( $p=$ .029), again with small effect sizes (see Table 1). In the post hoc analyses, differences on the Stroop-Color-Word were sig- nificant between the TD and DF groups $(p=.010)$, in favor of the former, but not between the ASD and DF groups $(p=$ $.207)$, or the ASD and TD groups $(p=.722)$; differences were significant on Stroop-Interference between the DF and ASD groups $(p=.037)$, in favor of the latter, but not between the ASD and TD groups $(p=.118)$, or the DF and TD groups $(p=.999)$;

Concerning the second objective, comparing central coherence through the GEFT and Block Design assessments, ANOVA results indicated significant between-group differences on the GEFT Correct Answers measure $(\phi=.0001)$, with a small effect size (see Table 1). Post hoc analyses indicated that significant differences appear between the ASD and DF groups $(p=.002)$, and between the ASD and TD groups $(p=.0001)$, with the ASD group obtaining a higher score; significant differences do not appear between the DF and TD groups $(p=.999)$. Regarding the Block design sub- 
test, ANOVA results showed significant between-group differences $(\phi=.012)$, with a small effect size (see Table 1). In the post hoc analyses, the differences were significant between the ASD and TD groups $(p=.018)$, and between the ASD and DF groups $(p=.046)$, in both cases with higher scores for the ASD children; differences were not significant between the DF and TD groups $(p=.999)$.

\section{Discussion}

Given the importance of EF in social and academic adjustment, and the fact that children with ASD and children from DF appear to present similar EF deficits, though caused by different reasons (disability or social situation, respectively); the main objective of this study was a between-group comparison of performance on different measures of EF. Children in one group were from disadvantaged families, another group was made up of children with ASD, without accompanying intellectual or language impairment; these two groups were compared with a group of children with typical development, in order to ascertain the level of deficit and its typology in each group and to develop appropriate intervention programs.

For the first objective, results show that our initial hypothesis is partially confirmed. As we expected, there were significant between-group differences on most measures used, except for the WCST-64; however, the TD group did not obtain the best scores in comparison to the other two groups, as we expected.

Only with respect to the DF group did the TD group obtain better scores, although the between-group differences were not significant in every case. Consequently, regarding the DF group, results obtained do concur with our hypothesis; because these children in general tended to obtain the worst scores on practically all measures used, as expected. These results concur with prior studies that also point to lower performance on different measures of EF in this group (Arán-Filippetti, 2013; Arán-Filippetti \& Richaud de Minzi, 2011; Mata et al., 2017; Raver et al., 2013; Rhoades et al., 2011).

In contrast, results obtained by the ASD group do not concur with our hypothesis: contrary to expectations, these children obtained similar or even higher performance than children with TD on all EF measures used. These good scores obtained by the children with ASD confirm results obtained by De Vries and Geurts (2012), Robinson et al. (2009) and Troyb et al. (2014). Using direct performance measures equivalent to those used here, these studies report similar abilities to subjects with TD. This is not totally compatible, however, with studies from Mostert-Kerckhoffs et al. (2015), and Van Eylen et al. (2015), who indicate poorer results from ASD children on inhibitory control and attentional flexibility. We should keep in mind, however, that these studies show differing results in relation to the type of task, the child's severity of symptoms and his/her IQ.

Regarding the second objective, to investigate how these participants carry out information processing, our results support our hypothesis and the hypothesis of weak central coherence in children with ASD; the latter obtained higher scores than the other two groups on both the field dependence/independence task (GEFT) and the Block Design subtest of the WISC-IV. Performance on the Block Design subtest, according to a study by Shah and Frith (1993), is favored by weak central coherence, thereby suggesting that the ASD child presents less general information processing, and is more focused on the details, than children from DF or children with TD (Aljunied \& Frederickson, 2013; Booth \& Happé, 2018; Brunsdon et al., 2015). With regard to the DF group, there seems to be no negative effect on central coherence from the psychosocial deprivation that these children are exposed to. As indicated above, the results they obtained are similar to those in the TD group.

Turning to the comparative analysis of EF deficits in the ASD and DF groups, results showed that the deficits in the two groups were not comparable. Just as different causes are at the root of the EF deficits in the two populations, we find between-group differences in the typology of their deficits and the performance levels they present. Each group shows difficulty or superiority in different skills. Specifically, the children from DF showed poorer performance on Digit Span, which assesses working memory; Stroop-Interference, which assesses inhibitory control; and a GEFT outcome that would indicate stronger central coherence. They obtained lower scores, though not significantly so, on the rest of the executive function measures, with the exception of WCST64 Perseverations, which indicates rigidity; in this case, the ASD group presented a higher score, that is, greater rigidity. These results would indicate that intervention programs designed for the two groups must be different. We point to the fact that the children with AS did not show difficulty in wellstructured EF tasks, such as those used in this study; this tells us that intervention programs with this population should focus on open-ended EF tasks or tasks involving activities from daily life where different EFs come into play. In the case of the children from DF, however, intervention programs should focus on well-structured EF tasks at least in an initial phase, due to the difficulties they present; openended EF tasks can be addressed subsequently.

Taking the results as a whole, we observe that the data met our expectations regarding children from DF, showing diverse deficits in $\mathrm{EF}$, probably due to their living conditions (Bäckman \& Nilsson, 2011; Dickerson \& Popli, 2016). By contrast, in the case of the children with ASD, high scores were obtained on some measures of EF, and there were differences from the other two groups on measures of processing, as had been observed in other studies from Brunsdon et al., (2015), De Vries \& Geurts (2014), and Robinson et al. (2009). Although the differences were not significant, ASD subjects showed a greater number of perseverations on the WCST-64 and a higher score on field independence, indicative of weak central coherence. These results contrast with the better scores they obtained for the 
ability to resist interference, measured by the Stroop, and for inhibitory control. These differences between measures might be due to the more explicit instructions on the Stroop (as compared to the WCST-64), an aspect that seems to enhance the performance of ASD children. In short, intervention programs for the two groups should be differentiated in the skills they address. Children from DF will need to work on a wide variety of EFs, because they show generalized deficits. Programs for children with ASD, however, can focus more on unstructured, cognitive flexibility tasks, where they seem to show greater difficulty, or on tasks that require ascertaining general information, that is, central coherence.

In order to explain the results obtained, we must first keep in mind that group designs mask the very heterogeneous nature of the ASD populations. These designs do not reflect the reality of the different participants, which may include some subjects with serious difficulties and others without any difficulty (De Vries \& Geurts, 2014; Leung \& Zakzanis, 2014; Van Eylen et al., 2015). In our case we selected a group of subjects without accompanying intellectual or language impairment, that is, with average IQ and matched to the TD group: this perhaps triggered the finding of similarity or even superiority to the TD group in certain abilities, though not in others (Kalbfleisch \& Loughan, 2012). In this regard, it should be noted that certain studies and meta-analyses find EF deficits to be associated with symptom severity, a relationship that cannot be verified in our study (Mostert-Kerckhoffs et al., 2015).

Another possible factor is the type of measure used for assessment, since some studies have reported discrepancies between different measures (Van Eylen et al., 2015): namely, direct performance measures differed from third-party reports, with good scores obtained on direct performance measures but deficits appeared in the parental reports (Gómez-Pérez et al., 2016; Troyb et al., 2014). These results can also be attributed to a lack of ecological validity of the direct measures (Leung \& Zakzanis, 2014), which keeps these measures from reflecting the subjects' true deficits.

Also important when interpreting these results are the between-group differences with regard to gender: there are fewer females in the ASD group, perhaps because this disorder is mainly present in males. This difference may have influenced our results (Bölte, Duketis, Poustka, \& Holtmann, 2011; Lemon, Gargaro, Enticott, \& Rinehart, 2011). For example, some studies have indicated that girls with ASD show greater inhibition problems than boys (Lemon et al., 2011); or that Boys with ASD obtain higher scores than girls in the Block Design Test (Bölte et al., 2011). Such differential results between the sexes might explain the good scores that our group obtained on both the inhibition control measure and the Block Design subtest, given that our ASD group is mostly made up of boys. Nonetheless, other studies have indicated that there is no difference between the sexes on direct performance measures, at least in the normal population (Heaton, 1981; Yamamoto \& Imai-Matsumura, 2019).
As for the main study limitations, although an ample number of measures were used to represent different abilities that make up EF. All of these were well-structured EF tasks, where there are explicit instructions that indicate what the participant has to do and how. In contrast, open-ended EF tasks, where there are no explicit instruction about how to solve the task and participant has to implicitly infer the behavior, and third-party reports (when third parties judge others' performance on EF tasks), should also be included. These tasks have been found to be more ecologically valid and more sensitive in detecting EF impairment in ASD subjects (Van Eylen et al., 2015), and in order to compare the performance of the different groups on these different measures. This would make it possible to explore whether discrepancies appear between the different types of measures, and whether subjects with ASD show difficulty on some measures but not on others, as was found elsewhere. Additionally, one should be cautious in considering our results, given that the ASD group in this study possesses specific characteristics, namely, language skills and average IQ.

On the other hand, enlarging the sample size should always be considered when establishing between-group differences, and this is particularly relevant in the case of the ASD group. Keeping in mind the heterogeneity of this population in IQ, language skills and autistic symptomatology, a larger sample size would make it possible to form different ASD groups that could be compared between themselves as well as with other groups, and thus shed light on the specific characteristics of subjects who present difficulties in EF.

\section{Conclusions}

Thereby, having assessed different executive functions and compared the performance of the three groups of children who participated in this study, our main conclusion is that growing up in disadvantaged families has a clear, negative effect on children's EFs; this group in general shows the worst performance of the three groups. However, in the case of the subjects with ASD who participated in this study, contrary to what was expected, there was no clear negative effect, because these children attained similar or even higher scores than the children with typical development. Although we started with two groups that we thought would be comparable in terms of EF deficits; this clearly did not turn out to be so. The children from disadvantaged families presented a greater quantity and variety of difficulties than the ASD children, when their executive functions were assessed using direct performance measures. Therefore, it might be assumed that the EF deficits presented by the two groups are different in nature. The ASD children, however, show differences from the other two groups in field dependence/independence and perseverations, indicating certain differences in information processing, differences that should be considered in future studies. 
Acknowledgments.- We are grateful to the participants, their parents and staff from associations and schools. We also acknowledge the Andalusian Regional Government, Grant Proyecto de Excelencia 2012, P12-SEJ-560, for their support of this work.

\section{References}

Aljunied, M., \& Frederickson, N. (2013). Does central coherence relate to the cognitive performance of children with autism in dynamic assessments? Autism: The International Journal of Research and Practice, 17, 172-183. doi:10.1177/1362361311409960

American Psychiatric Association (2013). DSM-V. Diagnostic and statistical manual of mental disorders. Arlington, VA: American Psychiatric Association. American Psychiatric Association.

Arán-Filippetti, V. (2013). Structure and Invariance of Executive Functioning Tasks across Socioeconomic Status: Evidence from Spanish-Speaking Children. The Spanish Journal of Psychology, 16(101), 115. doi:10.1017/sjp.2013.102

Arán-Filippetti, V., \& Richaud de Minzi, M. C. (2011). A structural analysis of executive functions and socioeconomic status in school-age children: cognitive factors as effect mediators. The Journal of Genetic Psychology, 173, 393-416. doi:10.1080/00221325.2011.602374

Bäckman, O., \& Nilsson, A. (2011). Pathways to social exclusion - A lifecourse study. European Sociological Review, 27, 107-123. doi:10.1093/esr/jcp064

Blijd-Hoogewys, E. M. A., Bezemer, M. L., \& Van Geert, P. L. C. (2014). Executive functioning in children with ASD: An analysis of the BRIEF. Journal of Autism and Developmental Disorders, 44, 3089-3100. doi:10.1007/s10803-014-2176-9

Bölte, S., Duketis, E., Poustka, F., \& Holtmann, M. (2011). Sex differences in cognitive domains and their clinical correlates in higher-functioning autism spectrum disorders. Autism, 15, 497-511. doi:10.1177/1362361310391116

Booth, R. D., \& Happé, F. G. (2018). Evidence of Reduced Global Processing in Autism Spectrum Disorder. Journal of Autism and Developmental Disorders, 48, 1397-1408. doi:10.1007/s10803-016-2724-6

Brocki, K. C., \& Bohlin, G. (2004). Executive functions in children aged 6 to 13: A dimensional and developmental study. Developmental neuropsychology, 26, 571-593. doi:10.1207/s15326942dn2602_3

Brunsdon, V. E. A., Colvert, E., Ames, C., Garnett, T., Gillan, N., Hallett, V., ... Happé, F. (2015). Exploring the cognitive features in children with autism spectrum disorder, their co-twins, and typically developing children within a population-based sample. The Journal of Child Psychology and Psychiatry, 56, 893-902. doi:10.1111/jcpp.12362

De Paúl, J., \& Arruabarrena, M. I. (1999). Escalas de Bienestar Infantil de Magura y Moses. Un primer estudio para la validación de la versión española [Child well-being scales of Magura and Moses. A preliminary study for the validations of the Spanish version]. Intervención Psicosocial, 8, 89-107. Retrieved from http://www.copmadrid.org/webcopm/publicaciones/social/47562.pdf

De Vries, M., \& Geurts, H. M. (2012). Cognitive flexibility in ASD; Task switching with emotional faces. Journal of Autism and Developmental Disorders, 42, 2558-2568. doi:10.1007/s10803-012-1512-1

De Vries, M., \& Geurts, H. M. (2014). Beyond individual differences: Are working memory and inhibition informative specifiers within ASD? Journal of Neural Transmission, 121, 1183-1198. doi:10.1007/s00702-0141225-z

Devicienti, F., \& Poggi, A. (2011). Poverty and social exclusion: two sides of the same coin or dynamically interrelated processes? Applied Economics, 43, 3549-3571. doi:10.1080/00036841003670721

Diamond, A. (2013). Executive functions. Annual review of psychology, 64, 135168. doi:10.1146/annurev-psych-113011-143750

Dickerson, A., \& Popli, G. (2016). Persistent poverty and children's cognitive development: Evidence from the UK Millennium Cohort
Declaration of Conflicting Interests: We have not conflict of interest to disclose.

Funding: This work was supported by Andalusian Regional Government (Junta de Andalucía), Proyecto de Excelencia convocatoria 2012 [Grant, P12-SEJ-560].

Study. Journal of the Royal Statistical Society: Statistics in Society-Series A, 179, 535-558. doi:10.1111/rssa.12128

Golden, C. J. (2006). Stroop: Test de Colores y Palabras [Stroop: Color and Word test]. Madrid: TEA ediciones.

Gómez-Pérez, M. M., Calero, M. D., Mata, S., \& Molinero, C. (2016). Discrepancies between direct and indirect measures of interpersonal and neurocognitive skills in autism spectrum disorder children. Journal of Clinical and Experimental Neuropsychology, 38, 875-886. doi:10.1080/13803395.2016.1170106

Greve, K. W. (2001). The WCST-64: A standardized short-form of the Wisconsin Card Sorting Test. The Clinical Neuropsychologist, 15, 228-234. doi:10.1076/clin.15.2.228.1901

Hair, N. L., Hanson, J. L., Wolfe, B. L., \& Pollak, S. D. (2015). Association of Child Poverty, Brain Development, and Academic Achievement. JAMA Pediatrics, 169, 822-829. doi:10.1001/jamapediatrics.2015.1475

Heaton, R. K. (1981). The Wisconsin Card Sorting Test manual. Odessa, FL: Psychological Assessment Resources.

Hill, E. L. (2004). Evaluating the theory of executive dysfunction in autism. Developmental review, 24, 189-233. doi:10.1016/j.dr.2004.01.001

Huizinga, M., Dolan, C. V., \& Van der Molen, M. W. (2006). Age-related change in executive function: Developmental trends and a latent variable analysis. Neuropsychologia, 44, 2017-2036. doi:10.1016/j.neuropsychologia.2006.01.010

Iampietro, M., Giovannetti, T., Drabick, D. A. G., \& Kessler, R. K. (2012). Empirically defined patterns of executive function deficits in schizophrenia and their relation to everyday functioning: a personcentered approach. The Clinical Neuropsychologist, 26, 1166-1185. doi:10.1080/13854046.2012.721399

Kalbfleisch, M. L., \& Loughan, A. R. (2012). Impact of IQ discrepancy on executive function in high-functioning autism: insight into twice exceptionality. Journal of Autism and Developmental Disorders, 42, 390-400. doi:10.1007/s10803-011-1257-2

Kongs, S. K., Thompson, L. L., Iverson, G. L., \& Heaton, R. K. (2000). Wisconsin Card Sorting Test-64 Card Version (WCST-64). Odessa, FL: Psychological Assessment Resources.

Lemon, J. M., Gargaro, B., Enticott, P. G., \& Rinehart, N. J. (2011). Brief report: Executive functioning in autism spectrum disorders: A gender comparison of response inhibition. Journal of Autism and Developmental Disorders, 41, 352-356. doi:10.1007/s10803-010-1039-2

Leung, R. C., Vogan, V. M., Powell, T. L., Anagnostou, E., \& Taylor, M. J. (2016). The role of executive functions in social impairment in Autism Spectrum Disorder. Child Neuropsychology: A Journal on Normal and Abnormal Development in Childhood and Adolescence, 22, 336-344. doi:10.1080/09297049.2015.1005066

Leung, R. C., \& Zakzanis, K. K. (2014). Brief report: Cognitive flexibility in autism spectrum disorders: A quantitative review. Journal of Autism and Developmental Disorders, 44, 2628-2645. doi:10.1007/s10803-014-2136-4

Lord, C., Rutter, M., DiLavore, P. C., y Risi, S. (2002). Escala de Observación de Diagnóstico de Autismo [Autism Diagnostic Observation Schedule, ADOS]. Madrid: TEA ediciones.

Magura, S., \& Moses, B. S. (1986). Outcome Measures for Child Welfare Services. Washington, D.C.: Child Welfare League of America.

Mata, S., Gómez-Pérez, M. M., Molinero, C., \& Calero, M. D. (2017). Interpersonal problem-solving skills, executive function and learning potential in preadolescents with high/low family risk. The Spanish Journal of Psychology, 20. e56. doi:10.1017/sip.2017.54

Mostert-Kerckhoffs, M. A. L., Staal, W. G., Houben, R. H., \& De Jonge, M. V. (2015). Stop and Change: Inhibition and Flexibility Skills Are 
Related to Repetitive Behavior in Children and Young Adults with Autism Spectrum Disorders. Journal of Autism and Developmental Disorders, 45, 3148-3158. doi:10.1007/s10803-015-2473-y

Moura, O., Simões, M. R., \& Pereira, M. (2015). Executive Functioning in Children with Developmental Dyslexia. The Clinical Neuropsychologist, 28(Suppl 1), 20-41. doi:10.1080/13854046.2014.964326

Peterson, R. K., Noggle, C. A., Thompson, J. C., \& Davis, J. J. (2015). Everyday executive functioning influences adaptive skills in autism spectrum disorders. Neuropsychological Trends, 18, 31-37. doi:10.7358/neur-2015-018-pete

Piovesana, A. M., Ross, S., Whittingham, K., Ware, R. S., \& Boyd, R. N. (2015). Stability of executive functioning measures in 8-17-year-old children with unilateral cerebral palsy. The Clinical Neuropsychologist, 29, 133-149. doi:10.1080/13854046.2014.999125

Pugliese, C. E., Anthony, L. G., Strang, J. F., Dudley, K., Wallace, G. L., Naiman, D. Q., \& Kenworthy, L. (2016). Longitudinal Examination of Adaptive Behavior in Autism Spectrum Disorders: Influence of Executive Function. Journal of Autism and Developmental Disorders, 46, 467-477. doi:10.1007/s10803-015-2584-5

Raver, C. C., Blair, C., \& Willoughby, M. (2013). Poverty as a predictor of 4-year-olds' executive function: New perspectives on models of differential susceptibility. Developmental Psychology, 49, 292-304. doi: $10.1037 / \mathrm{a} 0028343$

Rhoades, B. L., Greenberg, M. T., Lanza, S. T., \& Blair, C. (2011). Demographic and familial predictors of early executive function development: Contribution of a person-centered perspective. Journal of Experimental Cbild Psychology, 108, 638-662. doi:10.1016/j.jecp.2010.08.004

Robinson, S., Goddard, L., Dritschel, B., Wisley, M., \& Howlin, P. (2009). Executive functions in children with Autism Spectrum Disorders. Brain and Cognition, 71, 362-368. doi:10.1016/j.bandc.2009.06.007

Rutter, M., LeCouteur, A., Lord, C. (2000). Entrevista Diagnóstica del AutismoRevisada [Autism Diagnostic Intervien-Revised, ADI-R]. Madrid: TEA ediciones.
Shah, A., \& Frith, U. (1993). Why do autistic individuals show superior performance on the block design task? Journal of Child Psychology and Psychiatry, 34, 1351-1364. doi: 10.1111/j.1469-7610.1993.tb02095.x

Salomone, S., Fleming, G. R., Bramham, J., O'Connell, R. G., \& Robertson, I. H. (2016). Neuropsychological Deficits in Adult ADHD Evidence for Differential Attentional Impairments, Deficient Executive Functions, and High Self-Reported Functional Impairments. Journal of Attention Disorders. Advance online publication. doi: $10.1177 / 1087054715623045$

Troyb, E., Rosenthal, M., Eigsti, I. M., Kelley, E., Tyson, K., Orinstein, A., ... Fein, D. (2014). Executive functioning in individuals with a history of ASDs who have achieved optimal outcomes. Child Neuropsychology: $A$ Journal on Normal and Abnormal Development in Childhood and Adolescence, 20, 378-397. doi:10.1080/09297049.2013.799644

Ursache, A., \& Noble, K. G. (2016). Neurocognitive development in socioeconomic context: Multiple mechanisms and implications for measuring socioeconomic status. Psychophysiology, 53, 71-82. doi:10.1111/psyp.12547

Van Eylen, L., Boets, B., Steyaert, J., Wagemans, J., \& Noens, I. (2015). Executive functioning in autism spectrum disorders: influence of task and sample characteristics and relation to symptom severity. European Cbild \& Adolescent Psychiatry, 24, 1399-1417. doi:10.1007/s00787-0150689-1

Wechsler, D. (2005). Escala de inteligencia de Wechsler para niños-IV (WISC-IV). Wechsler intelligence scale for cbildren - IV]. Madrid: TEA ediciones.

Witkins, H. A., Oltman, P. K., Raskin, E., \& Karp, S. A. (1987). Tests de Figuras Enmascaradas [Embedded Figures Test]. Madrid: TEA ediciones.

Yamamoto, N., \& Imai-Matsumura, K. (2019). Gender differences in executive function and behavioural self-regulation in 5 year old kindergarteners from East Japan. Early Child Development and Care, 189, 56-67. doi:10.1080/03004430.2017.1299148

Zabel, T. A., Jacobson, L. A, Zachik, C., Levey, E., Kinsman, S., \& Mahone, E. M. (2011). Parent- and self-ratings of executive functions in adolescents and young adults with spina bifida. The Clinical Neuropsychologist, 25, 926-941. doi:10.1080/13854046.2011.586002 